\title{
Relationship between maternal hemoglobin and birthweight in Antioquia, Colombia
}

Carolina Madrid-Pérez 1

iD https://orcid.org/0000-0003-3875-7351

Sandra L Restrepo-Mesa 2

(iD) https://orcid.org/0000-0002-3938-4238

Jessica Aristizábal Tirado 3

(iD https://orcid.org/0000-0002-6511-2930

Diana Carolina Londoño Sierra 4

iD https://orcid.org/0000-0002-1248-2006

\author{
Arturo Cardona Ospina 5 \\ (iD) https://orcid.org/0000-0002-6171-7262 \\ Beatriz Elena Parra-Sosa 6 \\ (iD) https://orcid.org/0000-0001-8808-7515
}

1,3,4 School of Nutrition and Dietetics. Universidad de Antioquia. Medellín, Antioquia, Colombia
2,6 Food and Human Nutrition Research Group. School of Nutrition and Dietetics. Universidad de Antioquia. Calle 70 n. 52-21 Ventanilla única U. de A. Medellín, Antioquia,
Colombia. E-mail: beatriz.parra@udea.edu.co
5 Clínica del Prado Research Group. Universidad CES. Medellín, Colombia.

\begin{abstract}
Objectives: to determine the relationship between maternal hemoglobin (HbM) per gestational trimester and birthweight $(B W)$.

Methods: this was an analytical, cross-sectional observational study that included the prenatal records of 494 pregnant women who delivered live newborns in the Department of Antioquia. The maternal health data collected included $H b M$ and $B W$, and gynecological and obstetric, anthropometric, and maternal health-related data. The Mann-Whitney U test was applied, supplemented by effect size (ES) to compare the study groups.

Results: HbM in the third trimester was significantly associated with $B W(p=0.029)$. It showed a significant effect size on BW as follows: first trimester: $E S=0.44(C 195 \%=$ 0.183-0.697); second trimester: $E S=0.49(C 195 \%=0.187-0.79)$; and third trimester: $E S=0.43(C 195 \%=0.202-0.658)$. Maternal anemia was $4.2 \%, 11.2 \%$, and $21.4 \%$ in the first, second, and third trimester, respectively.

Conclusions: as it is an inexpensive indicator and easy to determine, the timely monitoring and assessment of HbM is required owing to its importance in maternal and neonatal health, quality of life, and human capital development.

Key words Birth weight, Anemia, Maternal hemoglobin, Pregnancy, Prenatal
\end{abstract}

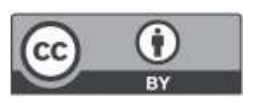




\section{Introduction}

Anemia is a nutritional problem that mainly affects women who are of reproductive age, pregnant women, and children under the age of 5 years; approximately $50 \%$ of cases are associated with iron deficiency. According to the 2011 global report, $38.2 \%$ of pregnant women have anemia. 1 The National Survey of the Nutritional Situation of Colombia (ENSIN) 2015 found anemia to be prevalent in $26.2 \%$ pregnant women aged between 13 and 49 years in Colombia, and $59.2 \%$ of these cases were due to iron deficiency; 2 according to the Food Nutritional Profile of Antioquia 2019, 48.4\% of pregnant women had anemia. 3 Low birthweight (LBW) is associated with highly preventable nutritional and maternal care factors. 4,5 In 2016, approximately 20 million infants with LBW were recorded globally from among the developing countries 6 and according to the Administrative Department of Statistics, Colombia had a LBW prevalence of $8.7 \% 7$ in 2014 and 9.2\% ${ }^{8}$ was recorded in Antioquia.

Anemia and LBW are important public health concerns associated with multiple factors and other health and nutrition determinants in women during their reproductive cycle. ${ }^{4}$ The study by Sukrat et al. ${ }^{9}$ and a meta-analysis of Ahankari et al. 10 are among the global studies analyzing the relationship between hemoglobin (HbM) during gestation and birthweight (BW) that coincide in affirming that low concentrations of $\mathrm{HbM}$ may affect BW. Furthermore, the study by Ahankari et al.10 also found an unfavorable effect between high concentrations of $\mathrm{HbM}$ and BW. In Colombia, some studies have found a relationship between these two variables of interest and the context of the populations where they were conducted, 11,12 but none were found to directly associate $\mathrm{HbM}$ concentration with BW. In MedellínAntioquia, there is some research that has addressed this problem, demonstrating the importance of maternal nutritional well-being on BW along with associated sociodemographic and gestational factors. ${ }^{13,14}$ However, there are no municipal studies, or any from the Department of Antioquia, on $\mathrm{HbM}$ and BW. Therefore, this study determined the relationship between $\mathrm{HbM}$ concentration during gestation and the BW of live newborns (LNB), in the Department of Antioquia (Colombia).

\section{Methods}

This was an analytical, cross-sectional observational study of pregnant women who had LNB in the Department of Antioquia in 2014 (75,907 births).
The study sample consisted of prenatal medical records of 494 pregnant women obtained from municipal public health institutions of the nine subregions in the Department of Antioquia. Inclusion criteria were monofetal LNB from a pregnancy, data on the weight and length at birth of the newborn whose mother had a prenatal clinical record and at least one $\mathrm{HbM}$ reading at the institution of the birth of her child, mother's age at the time of birth between 15 and 40 years, healthy except for anemic conditions, and/or iron deficiency. Exclusion criteria were multiple pregnancies, obesity, underweight, and high obstetric risk.

The sociodemographic variables were taken from the file recommended by the Latin American Center for Perinatology, Sexual and Reproductive Health of Women (CLAP) as follows: age, educational level classified as primary (from 1 to 5 years of study), secondary (from 6 to 11 years of study), and university (pre- and post-graduate, more than 12 years of study), marital status, area of residence (urban or rural), ethnic group, health regime (contributory, uninsured, or subsidized), and their classification in the System of Identification of Social Program Beneficiaries (SISBEN). This regime places citizens in levels from zero to five, depending on their social and economic conditions, with level zero being the most deprived and vulnerable up to level five, who have the best conditions. Other variables were gynecological and obstetric: type of delivery, number of prenatal consultations, parity, weight of the last child, birth interval as reported in the CLAP file, referring to the time that has elapsed between the birth date of the last child and the beginning of the next pregnancy, planned or desired pregnancy; and anthropometric: pre-pregnancy or first trimester weight and height (body height), to eva-luate body mass index (BMI), as inclusion criterion.In cases where these data were not available, BMI was selected before week 20 to rule out pregnant women with obesity or those underweight in accordance with the Comprehensive Care Guidelines from the Ministry of Health and Social Protection of Colombia. 15

$\mathrm{HbM}$ concentrations were taken from the clinical laboratory results of each health institution using the modified cyanmethemoglobin method 16 and later corrected according to altitude; the gestational age corresponding to each $\mathrm{HbM}$ was established by echography and these data defined the gestational trimester that corresponded to the HbM reading. Data obtained from the LNB included gestational age at birth, type of delivery, gender, BW, length, and head circumference. Weight was evaluated as a 
continuous variable, as a ratio, to establish its correlation with $\mathrm{HbM}$ concentration and the $\mathrm{BW}$ categories were: for those born at full term, the World Health Organization (WHO) 4 classification system was used and the macrosomic cut-off according to Tamez-Perez et al.17 (very LBW less than 1,499g, LBW less than 2500g, insufficient BW 2,500-2,999g; normal weight 3,000-4,000g, and macrosomic more than $4,000 \mathrm{~g}$ ); and for preterm patients, Fenton et al. 18 was used. The data collection was conducted using a previously adjusted and tested form designed by the group of researchers. Trained dietitian nutritionists made up the fieldwork staff.

For the description of the social demographic, gynecological and obstetric, and anthropometric aspects of the mother and the neonate, absolute and relative distributions were used with their 95\% confidence intervals (CI95\%) and summary indicators such as arithmetic mean, standard deviation, quartiles, and interquartile range. The Kolmogorov-Smirnov test was applied to assess the normality of the data. To calculate the delta (result of a mathematical operation, in this case, the difference in values) between the $\mathrm{HbM}$ of the first and third trimesters, the Wilcoxon signed-rank test was used. The relationship between HbM per gestation trimester and BW was determined using Spearman's correlation coefficient and the $\mathrm{HbM}$ per trimester was compared with the LNB weight categories (less than 3,000g and 3,000-4,000g) using the Mann-Whitney U test, supplemented with ES by means of probability of superiority (PS), where the following refe-rence values were taken: small ES between 0.1 and 2.9, medium between 0.3 and 0.49 , and large $\geq 0.519$ and the Eta coefficient squared, for the multivariate regression model. Multivariate regression was applied as an exploratory method by means of a generalized linear model of Poisson regression, with robust variance to adjust the proportion ratio (PR) and its CI95\%, by multiple variables, in order to evaluate the effect of some maternal gynecological and obstetric characteristics in the classification of BW. For this, two categories of BW were outlined, based on biological plausibility, as follows: less than $3,000 \mathrm{~g}$ and between $3,000 \mathrm{~g}$ and $4,000 \mathrm{~g}$; the first included insufficient weight and underweight and the second included newborns of normal weight according to the WHO criteria, as mentioned in the LBW protocol. ${ }^{4}$ A $p$ value $<0.05$ was considered to be statistically significant. The data were processed using the SPSS version 23 program and the R Studio program, version 3.5.0.

The research was endorsed by the Bioethics
Committee for Research in Humans at the University Research Headquarters (SIU- Universidad de Antioquia No. 17-69-761) and was carried out within the framework of resolution 8430 of 1993-Ministry of Health, the Declaration of Helsinki, and Resolution 839 of 2017-Ministry of Health and Social Protection of Colombia.

\section{Results}

The social demographic, gynecological and obstetric, and anthropometric characteristics of the pregnant women are described in Table 1. Regarding the level of education, the highest proportion of mothers had a high school-level $(71.1 \%)$ education and $7.7 \%$ had no education; the majority resided in the urban areas of the Department of Antioquia (84\%). The proportion of pregnant women who were single was $36.0 \%$; furthermore, $77.3 \%$ belonged to level 1 of the SISBEN who were allowed by the national government to access social and health programs for people with very low social and economic resources. Gynecological and obstetric results revealed that only $27.1 \%$ of women had planned the pregnancy and $17.4 \%$ had had a previous abortion; only $20 \%$ of mothers had intergametic interval data in their prenatal record. Regarding the anthropometric data, median weight and pre-pregnancy BMI were $58 \mathrm{~kg}(53 ; 63)$ and $23.2 \mathrm{~kg} / \mathrm{m}^{2}$ $(21.7 ; 24.9)$, respectively; median body height was $157 \mathrm{~cm}(153 ; 162)$.

Regarding HbM, $63 \%$ of measurements $(n=312)$ were obtained in the first trimester, with median $12.8 \mathrm{~g} / \mathrm{dL}$ and interquartile range $1.4 \mathrm{~g} / \mathrm{dL} ; 13$ mothers (4.2\%) had anemia, 3 and 4 of whose condition continued in the second and third trimester, respectively. In the second trimester, $41.5 \% \mathrm{HbM}$ results were obtained $(\mathrm{n}=205)$, with median $11.9 \mathrm{~g} / \mathrm{dL}$ and interquartile range $1.5 \mathrm{~g} / \mathrm{dL} ; 23$ mothers $(11.2 \%)$ had anemia and 8 of these continued to have the diagnosis at the end of pregnancy. In the third trimester, $74.3 \% \mathrm{HbM}$ results were obtained $(\mathrm{n}=378)$, with median $11.9 \mathrm{~g} / \mathrm{dL}$ and interquartile range $1.5 \mathrm{~g} / \mathrm{dL}$; 81 cases of anemia $(21.4 \%)$ were evidenced, 8 of which were prevalent and 73 were new.

The anthropometric data and the nutritional classification of LNB are shown in Table 2. Mean BW was $3,225.5 \mathrm{~g} \pm 409.2$. LBW and macrosomia were presented in the same proportion (3\%) for each category $(n=15)$, and $23.5 \%$ of neonates $(n=116)$ were classified as having insufficient weight (Weight) $(2,500-2,999 \mathrm{~g})$. Preterm LNBs were classified as follows: $83.3 \%(\mathrm{n}=15)$ adequate weight, $16.7 \%$ 
$(n=3)$ large for gestational age; none had the condition of small for gestational age.

When evaluating the relationship between $\mathrm{HbM}$ by trimester of gestation and BW, a linear correlation was not found. However, a statistically significant difference was found between the HbM in the third trimester and BW $(p<0.029)$ when this variable was grouped into two categories according to biological plausibility (BW less than 3,000g and BW between $3,000 \mathrm{~g}$ and $4,000 \mathrm{~g}$ ). Furthermore, when evaluating the effect size (ES), this was medium and important (ES more than 0.4 ) for $\mathrm{HbM}$ in each trimester $(\mathrm{ES}=0.44,0.49$, and 0.43 in the first, second, and third trimester, respectively) and for the difference (delta) between $\mathrm{HbM}$ in the first and third trimesters $(\mathrm{ES}=0.50)$ (Table 3$)$.

In order to evaluate the relationship between the $\mathrm{HbM}, \mathrm{BMI}$, and several maternal gynecological and obstetric characteristics with $\mathrm{BW}$ according to the categories (BW less than $3000 \mathrm{~g}$ and BW between $3000 \mathrm{~g}$ and $4000 \mathrm{~g}$ ), a generalized linear Poisson regression model of robust variance was constructed. The candidate variables were chosen according to the criteria of statistical significance in the bivariate analysis and biological plausibility. Statistically significant differences were found between pre-pregnancy BMI and treated urinary tract infection (UTI) and BW (Table 4).

The decision of the significant variables was made by the adjusted PR in the multivariate model. Therefore, it is 2.53 times more likely for pregnant women with a UTI, even treated, to have a newborn weighing less than $3,000 \mathrm{~g}$ compared with pregnant women without a UTI, adjusted for the other variables $(\mathrm{PR}=2.53$; CI95\% $=1.24-5.18)$. In addition, the probability that a newborn has a weight less than $3,000 \mathrm{~g}$ changes by a factor of 0.90 for each increase of one unit in pre-pregnancy BMI, adjusted for the other variables $(\mathrm{PR}=0.90 ; \mathrm{CI} 95 \%=0.81-0.99)$.

\section{Discussion}

There was a statistically significant association between the $\mathrm{HbM}$ in the third trimester and BW by category, and a medium and significant ES of the $\mathrm{HbM}$ was evidenced in each trimester, on the weight of the LNB. The results between the HbM and BW are heterogeneous, $20-24$ which can be attributed to the treatment of the $\mathrm{HbM}$ variable in analysis because some researchers do not classify it by trimester of gestation and others assess it to define mothers with and without anemia, comparing its effect on BW, but without performing correlation analysis. Furthermore, the cut-off points for this diagnosis vary.

A review by Dewey et al.22 concluded that a low $\mathrm{HbM}$ at the beginning of pregnancy is associated with LBW and adverse outcomes such as preterm, small for gestational age, and stillbirth, with the relationship being weak or non-existent with the second and third trimester HbM. Bakacak et al. 20 stated that the first trimester $\mathrm{HbM}$ was significantly associated with the BW being notably lower in the mothers of neonates with LW. However, second and third trimester $\mathrm{HbMs}$ were not associated with BW. By contrast, the meta-analysis by Ahankari et al.10 showed that there was a greater effect of anemia on LBW in the first trimester compared with that in the second and third trimesters, and although this result was based on a small number of studies, it was corroborated by another meta-analysis by Figueiredo et al. 25 that also analyzed HbM in the first trimester and the adverse outcomes, with a significantly higher study size. This investigation also found a medium and important ES value of the first trimester $\mathrm{HbM}$ on the BW, as well as an effect of the second and third trimester HbMs on this LNB variable.

Urdaneta et al. 23 found a directly proportional and significant correlation between $\mathrm{HbM}$ and $\mathrm{BW}$ concentration $(\mathrm{r}=0.439 ; p<0.0001)$, thus confirming the importance of this maternal protein in pregnancy outcomes. However, another investigation that analyzed the relationship between $\mathrm{HbM}$ and maternal serum iron levels in the third trimester, with BW and other pregnancy outcomes, 26 found no correlation or association between them.

In a study where there was a significant correlation between $\mathrm{HbM}$ and $\mathrm{BW}$, in the group of mothers with anemia, it was observed that the gestation trimester was taken into account for the analysis, however, the maternal nutritional status, as an intervening variable, was not included. 27 Sacramento et al.24 found no correlation between $\mathrm{HbM}$ during pregnancy and $\mathrm{BW}$, except in the third trimester and among mothers with anemia. A similar result was evidenced in the meta-analysis of five studies conducted by Ahankari et al. 10 which showed that the LNB of women with anemia were, on average, $303 \mathrm{~g}$ underweight compared with those who were born to mothers without anemia.

Regarding the difference or the $\mathrm{HbM}$ delta between the first and third trimesters, few studies evaluate the effect of this change on BW; to this regard, the study by Bakacak et al. 20 estimated the effect of the difference between $\mathrm{HbM}$ in the first and third trimesters (delta) on the BW categories and showed an LBW trend, wherein mothers had a lower change and with less variation, with respect to the 


\section{Table 1}

Sociodemographic, gynecological and obstetric, and anthropometric characteristics of the pregnant women. AntioquiaColombia.

\begin{tabular}{|c|c|c|}
\hline Pregnant woman & $\mathrm{N}=494$ & Frequency \% (C195\%) \\
\hline Age in years & & Me: $22(19 ; 27)^{a}$ \\
\hline \multicolumn{3}{|l|}{ Educational level (years of study) } \\
\hline None & 38 & $7.7 \%(5.5-10.1)$ \\
\hline From 1 to 5 & 71 & $14.4 \%(11.3-17.8)$ \\
\hline From 6 to 11 & 351 & $71.1 \%(66.6-74.9)$ \\
\hline More than 12 & 34 & $6.9 \%(4.9-9.3)$ \\
\hline \multicolumn{3}{|l|}{ Residence area } \\
\hline Urban & 415 & $84.0 \%(80.8-87.0)$ \\
\hline Rural & 79 & $16.0 \%(13.0-19.2)$ \\
\hline \multicolumn{3}{|l|}{ Ethnicity } \\
\hline Mixed race & 256 & $51.8 \%(47.2-56.3)$ \\
\hline Black & 19 & $3.8 \%(2.2-5.7)$ \\
\hline Indigenous & 4 & $0.8 \%(0.2-1.8)$ \\
\hline Other & 215 & $43.5 \%(39.3-48.2)$ \\
\hline \multicolumn{3}{|l|}{ Marital status } \\
\hline Common law marriage & 266 & $53.8 \%(49.4-58.1)$ \\
\hline Single & 178 & $36.0 \%(31.6-40.5)$ \\
\hline Married & 43 & $8.7 \%(6.3-11.3)$ \\
\hline Other & 7 & $1.4 \%(0.4-2.6)$ \\
\hline \multicolumn{3}{|l|}{ Health regime } \\
\hline Subsidized & 426 & $86.2 \%(83.0-89.3)$ \\
\hline Uninsured & 55 & $11.1 \%(8.3-14.0)$ \\
\hline Contributive & 13 & $2.6 \%(1.4-4.0)$ \\
\hline \multicolumn{3}{|l|}{ SISBENb level } \\
\hline Level 0 & 8 & $1.6 \%(0.6-2.8)$ \\
\hline Level 1 & 382 & $77.3 \%(73.7-81.4)$ \\
\hline Level 2 & 78 & $15.8 \%(12.6-19.2)$ \\
\hline Level 3 & 25 & $5.1 \%(3.2-7.1)$ \\
\hline Level 4 & 1 & $0.2 \%(0.0-0.6)$ \\
\hline \multicolumn{3}{|l|}{ Gynecology and obstetrics } \\
\hline Previous pregnancies & 273 & $55.3 \%(50.8-59.5)$ \\
\hline Previous abortions & 86 & $17.4 \%(14.4-20.6)$ \\
\hline Previous deliveries & 231 & $46.8 \%(42.1-51.2)$ \\
\hline Planned pregnancy & 134 & $27.1 \%(23.1-31.2)$ \\
\hline Birth interval & 101 & $20.4 \%(16.8-23.9)$ \\
\hline Cesarean & 145 & $29.4 \%(25.3-33.4)$ \\
\hline Treated UTIC & 21 & $4.3 \%(2.4-6.1)$ \\
\hline \multicolumn{3}{|l|}{ Anthropometrics } \\
\hline Pregestational BMId & 494 & Me: $23.2(21.7 ; 24.9)^{a}$ \\
\hline Pregestational height $(\mathrm{cm})$ & 494 & Me: $157(153 ; 162)$ a \\
\hline Pregestational weight $(\mathrm{kg})$ & 494 & Me: $58(53 ; 63)$ a \\
\hline BMId at last prenatal examination & 494 & Me: $27.2(25.8 ; 29.0)$ a \\
\hline
\end{tabular}

a Data are shown in Me: median (lower quartile; upper quartile); b Health beneficiary identification system; c Urinary tract infection; d Body mass index. 
Table 2

\begin{tabular}{lcc}
\hline \multicolumn{2}{l}{ Anthropometric data and nutritional classification of live newborns. Antioquia-Colombia. } \\
\hline Newborn & $\mathrm{N}=494$ & Frequency \% (Cl95\%) \\
\hline Anthropometric data & & $3225.5 \pm 409,2 \mathrm{a}$ \\
Weight (g) & & Me: $34(33 ; 35)^{\mathrm{b}}$ \\
Head circumference (cm) & & Me: $50(49 ; 51)^{\mathrm{b}}$ \\
Height (cm) & 231 & \\
Gender & 263 & $46.8 \%(42.5-51.0)$ \\
$\quad$ Female & 15 & $53.2 \%(49.0-57.5)$ \\
Male & 116 & $3.0 \%(1.6-4.7)$ \\
Weight classification WHOc,d & 348 & $23.5 \%(19.6-27.5)$ \\
$\quad$ Low birthweight & 15 & $70.5 \%(66.0-74.3)$ \\
Insufficient weight & & $3.0 \%(1.6-4.7)$ \\
$\quad$ Normal & 15 & $83.3 \%(62.5-100)$ \\
$\quad$ Macrosomic & 3 & $16.7 \%(0.0-36.3)$ \\
Fenton classificatione & 494 & Me: $39(38 ; 40) \mathrm{b}$ \\
$\quad$ Adequate & & \\
$\quad$ Large for gestational age & & \\
$\quad$ Gestational age & & \\
&
\end{tabular}

a Data are shown as arithmetic mean \pm standard deviation; bData are shown in Me: median (lower quartile; upper quartile); cWorld Health Organization; d Based on the Public Health Surveillance Protocol, low birth weight at term code 110, 2016.4; eBased on the Fenton classification. 18

Table 3

Ratio of maternal hemoglobin by gestation trimester and delta of hemoglobin with birthweight, Antioquia-Colombia.

\begin{tabular}{|c|c|c|c|c|}
\hline & $\begin{array}{l}\text { Weight }<3000(g) \\
\qquad(N=131)\end{array}$ & $\begin{array}{l}\text { Weight } 3000-4000(g) \\
\qquad(N=348)\end{array}$ & $p^{a}$ & $\begin{array}{l}\text { bEffect size } \\
\text { (Cl95\%) }\end{array}$ \\
\hline $\mathrm{HbM}$ in first trimester $(\mathrm{g} / \mathrm{dL})$ & $13.0(1.1) \mathrm{n}=79$ & $12.8(1.4) n=224$ & 0.093 & $0.44(0.183-0.697)$ \\
\hline $\mathrm{HbM}$ second trimester $(\mathrm{g} / \mathrm{dL})$ & $11.8(1.1) n=60$ & $11.9(1.6) n=138$ & 0.855 & $0.49(0.187-0.793)$ \\
\hline $\mathrm{HbM}$ third trimester $(\mathrm{g} / \mathrm{dL})$ & $12.1(1.2) n=103$ & $11.8(1.6) n=262$ & 0.029 & $0.43(0.202-0.658)$ \\
\hline \multicolumn{5}{|l|}{ HbM DELTA first trimester } \\
\hline vs third $(\mathrm{g} / \mathrm{dL})$ & $0.85(1.2) n=62$ & $0.9(1.3) n=165$ & 0.930 & $0.50(0.208-0.792)$ \\
\hline
\end{tabular}

Data are shown as median (interquartile range); a Mann-Whitney U; b Effect size: probability of superiority (PS). 
Hemoglobin concentration, body mass index, and some maternal gynecology and obstetrics characteristics according to birthweight, Antioquia-Colombia.

\begin{tabular}{|c|c|c|c|c|}
\hline & Weight $<3000$ (g) & Weight $3000-4000(\mathrm{~g})$ & $\begin{array}{l}\text { Value } p \text { adjusteda } \\
\text { (PR: Cl95\%) }\end{array}$ & $\begin{array}{c}\text { Effect size } \\
\text { Eta squaredb }\end{array}$ \\
\hline $\mathrm{HbM}$ first trimesterc $(\mathrm{g} / \mathrm{dL})$ & $13.0(1.1)$ & $12.8(1.3)$ & 0.494 (1.08: 0.87-1.33) & 0.0023 \\
\hline $\mathrm{HbM}$ third trimesterc $(\mathrm{g} / \mathrm{dL})$ & $12.1(1.2)$ & $11.8(1.6)$ & 0.164 (1.18: 0.93-1.50) & 0.0007 \\
\hline Agec (years) & $21(7)$ & $22(8)$ & $0.255(0.97: 0.91-1.02)$ & 0.0004 \\
\hline BMId pregestationalc & $22.8(3.1)$ & $23.3(3.2)$ & 0.043 (0.90: 0.81-0.99) & 0.0287 \\
\hline BMId from the last prenatal examinationc & $27.3(3.3)$ & $27.2(3.1)$ & 0.497 (0.96: 0.87-1.07) & 0.0045 \\
\hline Previous pregnancies $\mathrm{n}(\%)$ & $67(25.6 \%)$ & $195(74.4 \%)$ & 0.908 (0.95: $0.40-2.25)$ & 0.0038 \\
\hline Previous history of abortions n (\%) & $27(32.1 \%)$ & $57(67.9 \%)$ & $0.232(1.55: 0.75-3.20)$ & 0.0052 \\
\hline Previous deliveries n (\%) & $54(24.4 \%)$ & $167(75.6 \%)$ & 0.988 (0.99: 0.44-2.22) & 0.0036 \\
\hline UTI n (\%)e & $9(45.0 \%)$ & $11(55.0 \%)$ & $0.011(2.53: 1.24-5.18)$ & 0.0014 \\
\hline
\end{tabular}

Delta: It does not apply because of collinearity; a Poisson regression of multivariate robust variance; bEffect size for a multiple linear regression model (dependent variable birthweight in grams); cMedian (Interquartile range); d Body mass index; eUrinary tract infection.

other groups, even when this relationship did not reach statistical significance. The researchers did not apply the ES in their results. This study explored the effect of the change, or the difference (delta), between the $\mathrm{HbM}$ in the first and third trimesters on the BW and found that this was medium and important. From the point of view of biological plausibility, HbM must have important physiological changes that help to support maternal and fetal health; therefore, for a healthy pregnancy, it is important and advisable to redefine the cut-off points and normal ranges, as well as the difference that this protein presents, according to the gestation trimester. The inconsistent results of some studies on the relationship between $\mathrm{HbM}$ and $\mathrm{BW}^{23}$ can be attributed to the treatment of the $\mathrm{HbM}$ variable in analysis as a result of not defining the trimester in which it was taken, as well as evaluating the $\mathrm{HbM}$ in order to define when anemia is present or absent and evaluating its relationship with the BW. In contrast, some investigations establish different cut-off points to define anemia in pregnancy. There are also studies with intervening confounding variables, without statistical treatment, which can bias the relationship between $\mathrm{HbM}$ and BW.14,27

In a study in Colombia that applied a multivariate regression model, the pre-pregnancy BMI showed a significant relationship with the BW (less than $3,000 \mathrm{~g}$ and between 3,000 and $4,000 \mathrm{~g}$ ); 14 however, this study only included women with adequate or overweight pre-pregnancy weight.

By contrast, a relationship was found between mothers with a treated UTI and neonates weighing less than $3,000 \mathrm{~g}$. Some research 28 has shown that these infections can negatively affect the BW, particularly when the mother does not receive timely treatment. It is worth clarifying that a significant number of mothers had UTI but were being treated.

This study showed an increase in anemia as gestation advanced,13 anemic pregnant women in the first trimester, 23 in the second, and 81 in the third, and showed low timely follow-up of their progress given the prevalence of some mothers with anemia during the entire gestation and poor control in avoiding the high number of new cases at the end of the pregnancy; a study carried out by Rahmati et al. 29 also reported an increase in anemia at the end of pregnancy attributable to higher fetal demand, the low intake and bioavailability of iron in the maternal diet, and inadequate supplementation. Currently, Colombia has the Comprehensive MaternalPerinatal Health Care Route 30 for prenatal care of mandatory compliance, which requires the $\mathrm{HbM}$ to be determined at three moments of gestation. However, at the date of this study and in the current prenatal records, only two readings are required, before and after the $20^{\text {th }}$ week of pregnancy; notwithstanding the aforementioned, this study and those conducted by others based on this context show that there is a lack of $\mathrm{HbM}$ monitoring from a maternal-fetal health point of view. It is necessary to prioritize cost-effective measures to maintain maternal health and not just monitor the $\mathrm{HbM}$ in order to diagnose gestational anemia.

Given the clinical significance of HbM during pregnancy, it is important to evaluate and monitor it in 
the different gestation trimesters and to strive for an adequate concentration that favors maternal and neonatal health and an adequate BW. This study found that the increase in pre-pregnancy BMI reduced the risk of having neonates weighing less than $3,000 \mathrm{~g}$ and the presence of a UTI, even if it had been treated, increased this probability. The influence of pre-pregnancy maternal weight 6 and the presence of infections on pregnancy 7 have been reported in several studies.

The main limitation of the study is that not all mothers had their HbM measured in each trimester, which could affect the sample size to establish the correlation. The Colombian health system requires only two $\mathrm{HbM}$ readings to be taken i.e., before and after the $20^{\text {th }}$ week of pregnancy.

In conclusion, studies on the relationship between HbM during pregnancy and BW have evaluated the statistical significance; however, to date, there are no known investigations that have determined the ES.

$\mathrm{HbM}$ is a low-cost, easy-to-determine indicator of iron status and a proxy for maternal nutritional status; therefore, its evaluation and follow-up during pregnancy is necessary in order to guarantee main-

\section{References}

1. WHO (World Health Organization). The global prevalence of anemia in 2011. Geneva; 2015.

2. Instituto Nacional de Salud, Instituto Colombiano de Bienestar Familiar, Universidad Nacional de Colombia. Encuesta Nacional de la Situación Nutricional ENSIN 2015; 2019.

3. Gobernación de Antioquia, Gerencia de Seguridad Alimentaria y Nutricional de Antioquia - MANÁ, Escuela de Nutrición y Dietética. Perfil alimentario y nutricional de Antioquia 2019; 2019.

4. Instituto Nacional de Salud, Ministerio de salud (CO) Protocolo de Vigilancia en Salud Pública, bajo peso al nace a término código 110. 2016 [citado 29 mayo 2018] Disponible en: https://www.ins.gov.co/buscadoreventos/Lineamientos/PRO $\% 20$ Bajo\%20peso\%20al\%20na cer_.pdf

5. Silva Campos CA, Barreto Malta M, Ribeiro Neves, Hatzlhoffer Lourenço B, Castro MC, Cardoso MA Gestational weight gain, nutritional status and blood pressure in pregnant women. Rev Saúde Pública. 2019; 53: 57.

6. Ministerio de Salud y Protección Social (CO). Plan Decenal de Salud Pública, PDSP, 2012 - 2021. Bogotá D.C; 2013 [citado 29 mayo 2018]. Disponible en: https //www.minsalud.gov.co/Documentos\%20y\%20Publicacion es/Plan $\% 20$ Decenal $\% 20$

$\% 20$ Documento $\% 20$ en $\% 20$ consulta $\% 20$ para $\% 20$ aprobaci $\% \mathrm{C} 3 \% \mathrm{~B} 3 n$.pdf. taining adequate concentrations that promote maternal-fetal health and contribute to the adequate BW. HbM monitoring and timely treatment are required to prevent anemia, especially because the risk of anemia increases as gestation progresses.

Other maternal factors, such as pre-pregnancy weight and preventing infection during pregnancy, must be taken into account to promote an adequate BW.

\section{Author's contribution}

Madrid-Pérez C: conception, final writing, revision, methodology, research, administration. RestrepoMesa SL: revision, research. Ospina AC: revision. Tirado JA: methodology, research. Sierra DCL: methodology, research. Parra-Sosa BE: conception, final writing, revision, methodology, research. All authors approved the final version of the article.

7. Instituto Nacional de Salud. Informe final de bajo peso a término. 2015 [citado 29 mayo 2018]. Disponible en: https://www.google.com/search?q=Instituto+Nacional+de+ salud-

informe + final + de + bajo + peso $+\mathrm{a}+\mathrm{t} \% \mathrm{C} 3 \% \mathrm{~A} 9 \mathrm{rmino} \% 2 \mathrm{C}+20$ 15. Ram $\% \mathrm{C} 3 \% \mathrm{ADrez}+\mathrm{PX}$. + Hallado\&oq=Instituto + Nacion al+de+salud-

informe + final + de + bajo + peso $+\mathrm{a}+\mathrm{t} \% \mathrm{C} 3 \% \mathrm{~A} 9 \mathrm{rmino} \% 2 \mathrm{C}+20$ 15.Ram\%C3\%ADrez+PX. ++ Hallado\&aqs $=$ chrome..69i57. 1998j0j9\&sourceid=chrome\&ie=UTF-8.

8. Secretaría de salud y protección social de Antioquia. Análisis de situación de salud. Antioquia 2010. 2012 [citado 29 mayo 2018]. Disponible en: https://www.minsalud.gov.co/plandecenal/Paginas/mapa/A nalisis-de-Situacion-Salud-Antioquia-2010.pdf

9. Sukrat B, Wilasrusmee C, Siribumrungwong B, McEvoy M, Okascharoen C, Attia J, et al. Hemoglobin concentration and pregnancy outcomes: a systematic review and meta-analysis. Biomed Res Int. 2013; 2013: 769057.

10. Ahankari A, Leonardi-Bee J. Maternal hemoglobin and birth weight: systematic review and meta-analysis. Int J Med Sci Public Health. 2015; 4 (4): 435-45.

11. Ortiz EI. Estrategias para la prevención del bajo peso al nacer en una población de alto riesgo, según la medicina basada en la evidencia. Colom. Med. 2001; 32(4):159-62.

12. Daza V, Jurado W, Duarte D, Gich I, Sierra-Torres CH, Delgado-Noguera M. Bajo peso al nacer: exploración de 
algunos factores de riesgo en el Hospital Universitario San José en Popayán (Colombia). Rev Colomb Obstet Ginecol. 2009; 60 (2): 124-34

13. Escudero LS, Parra BE, Restrepo SL. Factores sociodemográficos y gestacionales asociados a la concentración de hemoglobina en embarazadas de la red hospitalaria pública de Medellín. Rev Chil Nutr. 2011; 38 (4): 429-37.

14. Restrepo Mesa SL, Parra Sosa BE, Arias Gómez J, Zapata López N, Giraldo Díaz CA, Restrepo Moreno CM, et al. Estado nutricional materno y su relación con el peso al nacer del neonato, estudio en mujeres gestantes de la red pública hospitalaria de Medellín, Colombia. Perspect Nut Hum. 2012; 14(2):199-208. doi: 10.17533/udea.penh

15. Ministerio de Salud y Protección Social (CO), Colciencias Guía de Práctica Clínica para la prevención, detección temprana y tratamiento de las complicaciones del embarazo, parto o puerperio (GAI). 2013 [citado 30 mayo 2018]. Disponible en https://www.minsalud.gov.co/sites/rid/Lists/BibliotecaDigit al/RIDE/INEC/IETS/Gu\%C3\%ADa.completa.Embarazo.P arto.2013.pdf.

16. Organización Mundial de la Salud. Concentraciones de hemoglobina para diagnosticar la anemia y evaluar su gravedad. 2011 [citado 30 mayo 2018]. Disponible en https://apps.who.int/iris/bitstream/handle/10665/85842/WH O NMH NHD MNM 11.1 spa.pdf?ua=1

17. Tamez-Pérez HE, Garza-Garza LA, Hernández M, TamezPeña AL, Escobedo-Lobatón JM. La prevalencia de bajo peso al nacer y macrosomía en una clínica privada del norte de México. Endocrinol Diabetes Nutr. 2017; 64 (8):456-59. doi: 10.1016/j.endinu.2017.06.004

18. Fenton TR, Kim JH. A systematic review and meta-analysis to revise the Fenton growth chart for preterm infants. BMC Pediatr. 2013; 20 (13): 59.

19. Dominguez-Lara S. Cartas al director: Magnitud del efecto, una guía rápida. Educ Med. 2018; 19 (4): 251-4

20. Bakacak M, Avci F, Ercan O, Köstü B, Serin S, Kiran G, et al. The effect of maternal hemoglobin concentration on fetal birth weight according to trimesters. J Matern Fetal Neonatal Med. 2015; 28 (17): 2106-10.

21. Jwa SC, Fujiwara T, Yamanobe Y, Kozuka K, Sago H. Changes in maternal hemoglobin during pregnancy and birth outcomes. BMC Pregnancy Childbirth 2015; 15:80. doi: 10.1186/s12884-015-0516-1.

Received on September 16, 2020

Final version presented on December 16, 2020

Approved on December 30, 2020
22. Dewey KG, Oaks BM. U-shaped curve for risk associated with maternal hemoglobin, iron status, or iron supplementation. Am J Clin Nutr. 2017; 106 (6): 1694S-1702S.

23. Urdaneta Machado JR, Lozada Reyes M, Cepeda de Villalobos M, García I J, Villalobos I N, Contreras Benítez A, et al. Anemia materna y peso al nacer en productos de embarazo a término. Rev Chil Obstet Ginecol. 2015; 80 (4) 297-305.

24. Sacramento H, Panta O. Relación entre los niveles de hemoglobina durante la gestación con el peso del recién nacido en el Hospital II Chocope, ESSALUD. Rev Cienc Tecnol. 2017; 13 (4): 21-32.

25. Figueiredo A, Gomes-Filho I, Silva R, Pereira P, Mata F, Lyrio A, et al. Maternal Anemia and Low Birth Weight: A Systematic Review and Meta-Analysis. Nutrients 2018; 10 (5):601. doi: 10.3390/nu10050601.

26. Demmouche A, Lazrag A, Moulessehoul S. Prevalence of anaemia in pregnant women during the last trimester: Consequense for birth weight. Eur Rev Med Pharmacol Sci. 2011; 15(4):436-45

27. Huang L, Purvarshi G, Wang S, Zhong L, Tang H. The Influence of Iron-deficiency Anemia during the Pregnancy on Preterm Birth and Birth Weight in South China. J Food Nutr Res. 2015; 3 (9): 570-4. doi: 10.12691/jfnr-3-9-2

28. Iqbal F, Naqvi KZ, Ashfaq S, Memon E, Aziz S, Sultan S, et al. Association of Maternal Lower Urinary Tract Infection with Adverse Fetal Outcome in Terms of Preterm Labor and Low Birth Weight. J. Soc. Obstet. Gynaecol. Pak. 2017; 7(1): 33-37.

29. Rahmati S, Delpishe A, Azami M, Hafezi Ahmadi MR, Sayehmiri K. Maternal Anemia during pregnancy and infant low birth weight: A systematic review and Metaanalysis. Int J Reprod Biomed (Yazd). 2017; 15(3):125-34.

30. Bogotá. Ministerio de Salud y Protección Social. Lineamiento técnico y operativo de la Ruta Integral de Atención en Salud Materno Perinatal. Bogotá D.C; 2018. 